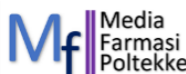 Poltekkes Makassar
}

\section{PENGARUH USIA DAN TINGKAT PENDIDIKAN TERHADAP PEMAHAMAN PASIEN SETELAH PELAYANAN INFORMASI OBAT DI PUSKESMAS MAKALE KABUPATEN TANA TORAJA TAHUN 2018}

\author{
Estherina Allo Payung1, Septyani Mambela ${ }^{2}$
}

\author{
1,2 Akademi Farmasi Toraja
}

*) Koresponden Author : estherinaallopayung@gmail.com / Tlp. 081342136015

https://doi.org/10.32382/mf.v14i2.586

\begin{abstract}
Pelayanan Informasi Obat adalah kegiatan pelayanan yang dilakukan oleh tenaga kefarmasian untuk memberikan informasi secara akurat, jelas dan terkini kepada pasien, dokter, apoteker, dan profesi kesehatan lainnya. Penelitian ini bertujuan untuk mengetahui hubungan antara usia dan tingkat pendidikan terhadap tingkat pemahaman pasien setelah diberikan Pelayanan Informasi Obat di Puskesmas Makale. Penelitian ini menggunakan observasi langsung di mana penulis mengumpulkan data dengan cara mengisi dan memberikan pertanyaan kepada pasien rawat jalan terkait dengan pemahaman pada pasien yang diberikan pelayanan tentang informasi obat. Populasi penelitian ini adalah seluruh pasien yang datang berobat di Puskesmas Makale Kabupaten Tana Toraja. Dengan sampel yaitu pasien rawat jalan di Puskesmas Makale Kabupaten Tana Toraja yang mendapatkan pelayanan pemberian informasi obat periode Juli - Agustus 2018. Penelitian ini pada 100 sampel di Puskesmas Makale diperoleh hasil rata -rata 43\% pada setiap pernyataan yang ada yaitu : Nama Obat, Bentuk Sediaan, Dosis obat, Cara Penggunaan, Cara Penyimpanan, Indikasi, Kontraindikasi, Stabilitas, Efek samping, Interaksi. Berdasarkan penelitian diperoleh hasil bahwa usia tidak memiliki hubungan dengan tingkat pemahaman pada pengaruh pemberian Pelayanan Informasi Obat dan tingkat pendidikan memiliki hubungan setelah pemberian Pelayanan Informasi Obat pada pasien rawat jalan di Puskesmas Makale.
\end{abstract}

Kata kunci : Pelayanan Informasi Obat, Puskesmas, Pemahaman, Hubungan Usia dan tingkat pendidikan

\section{PENDAHULUAN}

Menurut Peraturan Menteri Kesehatan Republik Indonesia Nomor 75 Tahun 2014 tentang Pusat Kesehatan Masyarakat menyatakan bahwa, Puskesmas adalah fasilitas pelayanan kesehatan yang menyelenggarakan Upaya Kesehatan Masyarakat (UKM) dan Upaya Kesehatan Perorangan (UKP), dengan lebih mengutamakan upaya kesehatan pemeliharaan, peningkatan kesehatan (promotif), pencegahan penyakit (preventif), penyembuhan penyakit (kuratif), dan pemulihan kesehatan (rehabilitatif), yang dilaksanakan secara menyeluruh, terpadu, dan berkesinambungan, untuk mencapai derajat kesehatan masyarakat yang setinggi-tingginya di wilayah kerjanya.

Upaya kesehatan adalah setiap kegiatan untuk memelihara dan meningkatkan kesehatan dan bertujuan untuk mengoptimalkan derajat kesehatan masyarakat, di mana hal tersebut dapat diperoleh melalui Pelayanan Informasi Obat secara tepat. Pelayanan Informasi Obat merupakan kegiatan pelayanan yang dilakukan oleh tenaga kefarmasian untuk memberikan informasi secara akurat, jelas dan terkini kepada pasien, dokter, apoteker, dan profesi kesehatan lainnya.

Tujuan Pelayanan Informasi Obat yaitu menyediakan informasi mengenai obat kepada tenaga kesehatan lain di lingkungan puskesmas, pasien dan masyarakat; Menyediakan informasi untuk membuat kebijakan yang berhubungan dengan obat; dan Menunjang penggunaan obat yang rasional (Peraturan Menteri Kesehatan Republik Indonesia Nomor 74 Tahun 2016).

Di Kabupaten Tana Toraja terdapat 21 Puskesmas salah satunya adalah Puskesmas Makale. Berdasarkan survei awal yang dilakukan hasil yang ditemukan yaitu 3 diantara 10 pasien yang berkunjung di Puskesmas Makale tidak paham mengenai informasi obat meskipun sudah diberikan Pelayanan Informasi Obat dan tingkat kunjungan pasien di Puskesmas Makale terdapat sekitar \pm 40 pasien yang datang berobat setiap 
harinya dengan jumlah petugas kefarmasiaan sebanyak 2 orang. Data tersebut menjadi dasar untuk melakukan penelitian karena jumlah pasien yang datang lebih banyak dibandingkan dengan jumlah petugas kefarmasiaan. Kurangnya jumlah petugas kefarmasiaan dan banyaknya jumlah pasien setiap harinya dapat menyebabkan kurangnya pelayanan kefarmasiaan sehingga dapat mempengaruhi tingkat pemahaman pasien.

Profil Puskesmas Makale yaitu Puskesmas Makale terletak di jalan Nusantara Nomor 8, Kelurahan Bombongan, Kecamatan Makale, Kabupaten Tana Toraja, Provinsi Sulawesi Selatan, Indonesia, Lokasinya berada tepat di pusat kota Makale, Ibukota Kabupaten Tana Toraja. Lokasinya yang sangat strategis yaitu berada di jalan poros antara Kota Makale dan Rantepao, sangat mudah untuk diakses oleh masyarakat, tidak hanya oleh masyarakat Kecamatan Makale semata namun juga dari berbagai daerah di Kabupaten Tana Toraja.

Terdapat banyak faktor yang memengaruhi pemahaman antara lain usia, tingkat pendidikan (Kutner dkk, dan Santosa, 2012) termasuk informasi obat yang disampaikan oleh Apoteker atau tenaga kefarmasian. Informasi obat juga perlu dipertimbangkan dapat memengaruhi pemahaman karena adanya intervensi pemberian informasi obat dari apoteker memengaruhi peningkatan pengetahuan mengenai informasi obat. Adanya pengulangan informasi obat oleh pasien menunjukkan bahwa mereka mampu memahami apa yang disampaikan oleh apoteker.

Di sisi lain, pemahaman merupakan salah satu proses dari dua komponen utama dalam literasi kesehatan sehingga dari informasi kesehatan yang diberikan, individu dapat menerapkannya untuk mengobati atau mencegah penyakit. Sementara beberapa informasi obat yang diberikan di Puskesmas yang merupakan unit pelaksana teknis dinas kesehatan masih belum lengkap dimana informasi mengenai makanan/aktivitas yang harus dihindari selama penyembuhan jarang atau tidak disampaikan. Oleh karena hal-hal tersebut, perlu diketahui tingkat pemahaman dan kemungkinan faktor-faktor apa saja yang memengaruhinya termasuk pelayanan informasi obat yang telah diterima masyarakat di Puskesmas.

Usia merupakan faktor yang memengaruhi kemampuan dalam pemahaman seseorang. Individu yang berusia tua akan mengalami penurunan fungsi kognitif dan kemampuan berfikir. Oleh karena itu, seseorang yang berusia tua akan mengalami kesulitan untuk membaca dan memahami informasi kesehatan yang diberikan oleh tenaga kesehatan sehingga dapat memengaruhi literasi kesehatan.

Tingkat Pendidikan dimana pendidikan merupakan salah satu faktor yang signifikan terhadap literasi kesehatan (pemahaman), dimana faktor langsung yaitu memengaruhi kemampuan seseorang dalam membaca, mendengarkan, dan memahami informasi. Faktor tidak langsungnya yakni tingkat pendidikan berkaitan dengan pekerjaan yang dapat memengaruhi tingkat ekonomi dan memengaruhi kemampuannya dalam menyelesaikan masalah. Dengan demikian, seseorang mudah dalam mendapatkan serta memahami informasi obat. Adapun salah satu informasi obat yakni instruksi tertulis seperti aturan pakai. Individu yang memiliki tingkat pendidikan tinggi cenderung mudah dalam memahami label obat dan mudah mendapatkan informasi mengenai tindakan pencegahan penyakit. Sama halnya yang menyatakan bahwa dengan adanya pendidikan yang berkualitas dapat meningkatkan kemampuan kognitif seseorang sehingga dapat mengakses informasi obat yang akhirnya dapat membangun perilaku sehat sejak dini yang dapat digunakan sepanjang hidupnya.

Penelitian ini dilakukan untuk mengetahui tingkat pemahaman yang menggambarkan kualitas informasi obat yang diterima oleh pasien setelah diberikan Pelayanan Informasi Obat. Dalam penelitian ini akan dilihat apakah kegiatan pelayanan informasi obat yang diberikan dan dijalankan sudah memenuhi harapan pasien dipuskesmas. Hasil penelitian ini selanjutnya dapat digunakan sebagai usaha peningkatan pemahaman dan kualitas mutu pelayanan kefarmasian pada seluruh puskesmas yang ada di Indonesia khususnya di Tana Toraja. Rumusan masalah dalam penelitian ini adalah bagaimana hubungan antara usia dan tingkat pendidikan terhadap tingkat pemahaman pasien setelah diberikan Pelayanan Informasi Obat (PIO) di Puskesmas Makale?

\section{METODE}

\section{Jenis Penelitian, Tempat dan Waktu}

Jenis penelitian yang digunakan dalam penelitian ini adalah deskriptif dengan metode Prospektif. Tempat penelitian ini dilaksanakan di Puskesmas Makale Kabupaten Tana Toraja dan dalam waktu periode Juli - Agustus 2018

\section{Populasi, Sampel dan Teknik Sampling}


Populasi dari penelitian ini adalah seluruh pasien yang datang berobat di Puskesmas Makale Kabupaten Tana Toraja. Sampel dari penelitian ini adalah pasien rawat jalan di Puskesmas Makale Kabupaten Tana Toraja yang mendapatkan pelayanan pemberian informasi obat periode Juli - Agustus 2018. Teknik pemilihan sampel berdasarkan kriteria sebagai berikut :

1. Pasien yang berusia $>15$ tahun

2. Pasien yang memiliki tingkat pendidikan dari Tidak Sekolah, SD, SMP, SMA, D3, S1

3. Pasien yang dapat berkomunikasi

4. Pasien yang bersedia diwawancarai menjadi responden dan telah menandatangani lembar persetujuan (informed consent).

Teknik pengambilan sampel menggunakan teknik Purposive Sampling di mana pengambilan sampel diambil secara acak.

\section{Teknik pengumpulan Data}

Pengumpulan data dilakukan dengan menggunakan metode direct observation dimana penulis mengumpulkan data dengan cara mengisi dan memberikan pertanyaan kepada pasien rawat jalan terkait dengan pemahaman pada pasien yang diberikan pelayanan tentang informasi obat. Instrumen yang digunakan dalam penelitian ini adalah lembar test untuk melihat kepahaman pasien.

\section{Cara Analisis Data}

Penelitian ini dilakukan dengan cara uji deskriptif parametrik dengan metode korelasi persen (Pearson Correlation) antara usia dan tingkat pendidikan pasien dengan tingkat kepahaman terhadap informasi obat yang diberikan.

\section{HASIL}

Hasil penelitian menunjukkan pelayanan informasi obat yang dilakukan di Puskesmas Makale Kabupaten Tana Toraja pada 100 sampel pasien rawat jalan terdapat 10 pernyataan dan 10 pertanyaan wawancara yaitu : [nama obat (P1), bentuk sediaan (P2), dosis obat (P3), cara penggunaan obat $(\mathrm{P} 4)$, cara penyimpanan obat (P5), indikasi obat (P6), kontraindikasi (P7), stabilitas obat (P8), efek samping obat (P9), interaksi obat (P10)] diperoleh hasil bahwa tidak semua hasil wawancara memiliki hasil $100 \%$

\section{PEMBAHASAN}

Berdasarkan hasil penelitian yang dilakukan di Puskesmas Makale Kabupaten Tana
Toraja diperoleh hasil bahwa tidak semua hasil wawancara memiliki hasil $100 \%$ karena dari beberapa pasien tidak paham atau tidak mengerti dan petugas pelayanan kefarmasian tidak menjelaskan sebagian dari 10 pernyataan diatas yang seharusnya perlu dijelaskan tetapi karena keterbatasan waktu yang tidak memungkinkan bagi pasien untuk mendengarkan dan memperhatikan penjelasan dari petugas tenaga teknis kefarmasian.

Pada pemberian Pelayanan Informasi Obat oleh petugas tenaga teknis kefarmasian dalam mewujudkan mutu pelayanan kesehatan yang baik dan selalu memberikan pelayanan kefarmasian kepada yang menerima informasi obat.

Dengan pemberian informasi kepada pasien, maka dapat dijalin hubungan yang baik sehingga dapat mengurangi atau menghindarkan kemungkinan bisa terjadinya kesalahan penyerahan obat kepada pasien. Hal yang terpenting dalam melakukan kegiatan tersebut harus memenuhi 10 indikator Pelayanan Informasi Obat (PIO) yaitu tentang nama obat, bentuk sediaan, dosis obat, cara penggunaan obat, cara penyimpanan obat, indikasi obat, kontraindikasi, stabilitas obat, efek samping obat, interaksi obat.

Pentingnya nama obat (P1) yang diberikan kepada pasien agar mengetahui dan membedakan macam - macam obat tersebut, bentuk sediaan (P2) yang diberikan kepada pasien supaya dapat mengetahui bentuk dari obat - obat tersebut. Dosis obat (P3) yang diberikan kepada pasien sangatlah penting agar obat yang diberikan itu diminum secara teratur, cara penggunaan obat (P4) yang diberikan kepada pasien supaya dapat mengetahui bagaimana obat itu digunakan dengan baik dan benar. Cara penyimpanan obat (P5) yang diberikan kepada pasien sangatlah penting agar obat yang dikonsumsi bisa disimpan secara baik dan benar sehingga obat tidak mengalami kerusakan yang dapat mempengaruhi kegunaan obat.

Indikasi obat (P6) juga sangatlah penting bagi pasien agar dikonsumsi atau dipakai sesuai dengan kegunaan obat, kontraindikasi obat (P7) sangatlah penting agar pasien mengetahui dimana obat tidak boleh diberikan pada keadaan tertentu, serta stabilitas obat (P8) penting bagi pasien dimana pada obat harus diketahui penyimpanan obat dengan baik terutama pada obat yang memiliki pengaruh kualitas yang rendah. Sedangkan pada efek samping obat (P9) juga sangatlah penting agar pasien mengetahui masalah 
apa yang akan terjadi setelah konsumsi obat tersebut, dan interaksi obat (P10) juga penting bagi pasien karena dimana jika pada obat yang dikonsumsi tidak boleh dikonsumsi secara bersamaan harus berbeda jam ketika dikonsumsi tetapi pasien tidak paham jadi pasien konsumsi obat tersebut pada jam yang sama.

Dari hasil wawancara dengan responden dengan indikator nama obat (P1) diperoleh hasil $72 \%$ karena pada beberapa responden tidak begitu memperhatikan obat apa yang dikonsumsi mereka beranggapan bahwa obat yang diberikan oleh dokter harus diminum secara rutin setiap harinya dengan tetap memperhatikan aturan minumnya. Bentuk sediaan (P2) diperoleh hasil 0\% karena semua responden tidak begitu memperhatikan dan mengerti bentuk sediaan obat apa yang diberikan kepada mereka, petugas kefarmasian tidak menjelaskan hanya menuliskan bentuk sediaan tersebut dietiket obat. Dosis obat (P3) diperoleh hasil $80 \%$ karena pada beberapa responden sudah memahami dan mengerti dosis yang diberikan oleh petugas kefarmasian dan secara rutinitas sudah minum obat, cara penggunaan obat (P4) diperoleh hasil $100 \%$ karena semua responden memahami dan mengerti bahwa obat diminum dan salep itu harus dioleskan, cara penyimpanan obat (P5) diperoleh hasil 100\% karena semua responden memahami dan mengerti cara menyimpan obat dengan baik dan benar.

Indikasi obat (P6) diperoleh hasil 80\% karena pada beberapa responden sudah memahami dan mengerti indikasi atau khasiat obat itu untuk diminum, sesuai kegunaan penyakit yang ada didalam tubuhnya dan diminum secara teratur sesuia dengn aturan minum yang ada. Kontraindikasi (P7) diperoleh hasil 0\% karena keterbatasan waktu yang ada dan lamanya menyiapkan obat sehingga petugas kefarmasian tidak menjelaskan informasi tersebut yang seharusnya dijelaskan dengan jelas, baik dan benar. Stabilitas obat (P8) diperoleh hasil $0 \%$ karena keterbatasan waktu yang ada dan lamanya menyiapkan obat sehingga petugas kefarmasian tidak menjelaskan informasi tersebut yang seharusnya dijelaskan dengan jelas, baik dan benar karena petugas kefarmasian tidak menjelaskan. Efek samping obat (P9) diperoleh hasil $0 \%$ karena keterbatasan waktu yang ada dan lamanya menyiapkan obat sehingga petugas kefarmasian tidak menjelaskan informasi tersebut yang seharusnya dijelaskan dengan jelas, baik dan benar karena petugas kefarmasian tidak menjelaskan. Interaksi obat (P10) diperoleh hasil
0\% karena keterbatasan waktu yang ada dan lamanya menyiapkan obat sehingga petugas kefarmasian tidak menjelaskan informasi tersebut yang seharusnya dijelaskan dengan jelas, baik dan benar karena petugas kefarmasian tidak menjelaskan.

Dari setiap masalah yang ada saat ini di puskesmas harus mempunyai solusi atau pendapat yang berguna demi kelancaran pelayanan kefarmasian. Dari hasil penelitian diatas solusi yang dapat diberikan kepada Puskesmas yaitu Apoteker atau Tenaga teknik kefarmasian seharusnya menjelaskan semua indikator Pelayanan Informasi Obat khususnya kontraindikasi, stabilitas, efek samping, dan interaksi. Untuk pasien harus sabar mendengarkan apa yang akan dijelaskan petugas kefarmasian tentang obat tersebut.

Penelitian ini menggunakan skala ordinal yang mempunyai nilai tingkatan yang berbeda misalnya usia : 16 sampai 85 dan tingkat pendidikan : tidak sekolah, SD, SMP, SMA, D3, S1 dengan metode korelasi persen (Pearson Correlation) agar diketahui ada tidaknya hubungan yang terjadi pada pengaruh pemberian pelayanan informasi obat. Dikatakan uji parametrik multivariat menggunakan 3 variabel yaitu Pemahaman, Usia, Tingkat pendidikan karena hasil distribusi normalnya baik.

Berdasarkan analisis statistik dengan metode spermen dan diperoleh hasil bahwa pada penelitian dilakukan di Puskesmas Makale dengan jumlah sampel 100 pada pengaruh pemahaman pasien rawat jalan dengan melihat hubungan antara usia dan tingkat pendidikan setelah pemberian Pelayanan Informasi Obat dimana jika signifikan (2-tailed) $<0,05$ berarti memiliki hubungan jika signifikan (2-tailed) >0,05 berarti tidak memiliki korelasi. Usia diperoleh hasil Signifikan (2-tailed) yaitu 0.184 bahwa usia tidak memiliki hubungan dengan tingkat pemahaman dengan melihat pengaruh Pemberian Pelayanan Informasi Obat, sedangkan Tingkat pendidikan diperoleh hasil Signifikan (2-tailed) yaitu 0.000 pada tingkat pendidikan memiliki hubungan dengan tingkat pemahaman dengan melihat pengaruh Pemberian Pelayanan Informasi Obat.

\section{KESIMPULAN}

Berdasarkan hasil penelitian yang berjudul dengan menggunakan metode observasi langsung diperoleh hasil bahwa usia tidak memiliki hubungan dengan tingkat pemahaman pada pengaruh pemberian Pelayanan Informasi 
Obat dan tingkat pendidikan memiliki hubungan setelah pemberian Pelayanan Informasi Obat pada pasien rawat jalan di Puskesmas Makale.

\section{SARAN}

Disarankan untuk petugas kefarmasian harus memperhatikan dan menyampaikan berdasarkan usia dan pendidikan kepada pasien dalam melakukan Pelayanan Informasi Obat.

\section{DAFTAR PUSTAKA}

Arfaldi Andri. 2016. Makalah "Pelayanan Informasi Obat”. Program Studi S1 Farmasi Sekolah Tinggi Ilmu Farmasi Riau

Aslam Muhammad, Kaw Tan Chik, Adji Pra Yitno. 2003. Farmasi Klinis (Clinical Pharmacy) Menuju Pegobatan Rasional dan Penghargaan Pilihan Pasien. Surabaya. PT. Alex Media Komputindo

Pratama A. Dhewa. 2017. Hubungan Tingkat Pengetahuan Tentang Penerapan Patient
Safety Dengan Persepsi Penerapan Patient Safety. Universitas Diponegoro Semarang

Peraturan Menteri Kesehatan Republik Indonesia No.74 tahun 2016 tentang Standar Pelayanan Kefarmasian di Puskesmas

Peraturan Menteri Kesehatan Republik Indonesia No. 75 Tahun 2014 Tentang Pusat Kesehatan Masyarakat

Suciptawati P. L. Ni. 2016. Statistika Non Parmetrik. Universitas Udayana Bukit Jimbaran

Sri Rastantyo Duta. 2012. Penilaian Pasien Terhadap Peran Tenaga Kefarmasian Dalam Pemberian Informasi Obat Di Apotek Rawat Jalan Rumah Sakit Umum Daerah Dr. Moewardi Periode April-Mei 2012. Surakarta. Diploma III Farmasi Fakultas Matematika Dan Ilmu Pengetahuan Alam Universitas Sebelas Maret 
Tabel 1. Hasil data penelitian pada pelayanan informasi obat

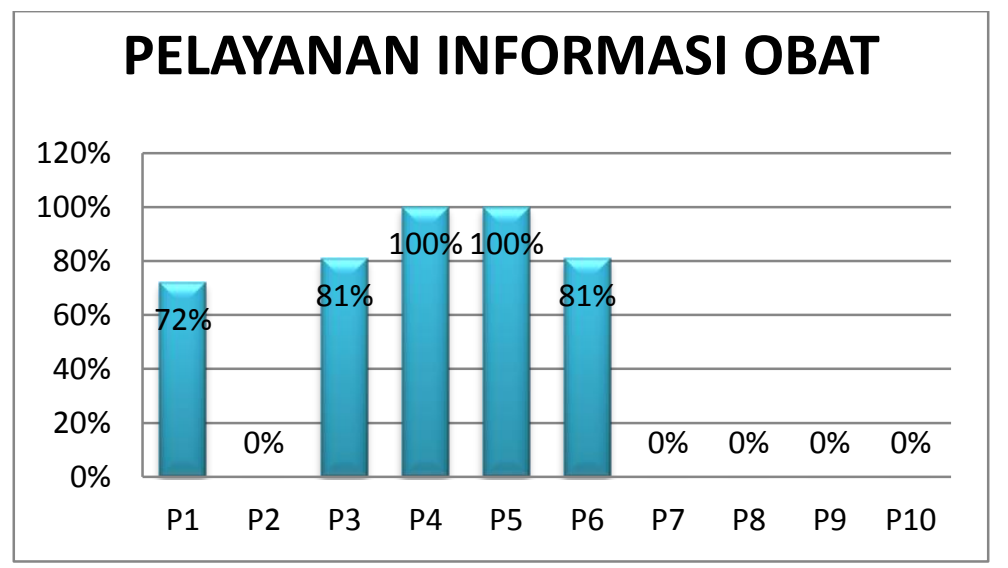

Grafik 1. Indikator Pemberian Pelayanan Informasi Obat

Tabel 2. Hubungan usia dan tingkat pendidikan pada pengaruh Pelayanan Informasi obat

\begin{tabular}{llrrr}
\hline \multicolumn{4}{c}{ Correlations } & \\
\hline & & USIA & PENDIDIKAN & NILAI \\
\hline USIA & 1 & -.024 & -.134 \\
& Pearson Correlation & & .812 & .184 \\
& Sig. (2-tailed) & 100 & 100 & 100 \\
\hline $\mathrm{N}$ & Pearson Correlation & -.024 & 1 & $.414^{* *}$ \\
& Sig. (2-tailed) & .812 & 100 & .000 \\
& $\mathrm{~N}$ & 100 & $.414^{* *}$ & 1 \\
\hline NILAI & Pearson Correlation & -.134 & .000 & \\
& Sig. (2-tailed) & .184 & 100 & 100 \\
\hline N & 100 & &
\end{tabular}




\section{MEDIA FARMASI}

POLITEKNIK KESEHATAN MAKASSAR

Penasehat

Penanggung Jawab

Dewan Redaksi

Ketua

Anggota

Mitra Bestari

Alamat Redaksi
: Direktur Politeknik Kesehatan Kemenkes Makassar

: Ketua Jurusan Farmasi Politeknik Kesehatan

Kemenkes Makassar

: $\quad$ Santi Sinala, S,Si, M.Si, Apt

: Hendra Stevani, S.Si, M.Kes, Apt

Sisilia Teresia Rosmala Dewi, S.Si, M.Kes, Apt

Muli Sukmawaty, S.Farm, Apt

Muhammad Riswan, S.Kom

: $\quad$ Dr. Islamudin Ahmad, M.Si,Apt (Universitas Mulawarman)

DR. Rusli, Sp.FRS, Apt

DR. Hj. Nurisyah, M.Si, Apt (Poltekkes Makassar)

DR. Sesilia Rante Pakadang, M.Si, Apt (Poltekkes Makassar)

DR. H. Asyhari Asyikin, S.Farm, M.Kes (Poltekkes Makassar)

: Jurusan Farmasi

Politeknik Kesehatan Kementerian Kesehatan Makassar

J1. Baji Gau No.10 Makassar

Telp. 0411-854021, 830883 Fax. 0411-830883

Kode pos 90134

Website :

http://journal.poltekkes-mks.ac.id/ojs2/index.php/mediafarmasi/index 


\section{EDITORIAL}

Pembaca yang budiman, ucapan syukur Alhamdulillah kami panjatkan ke hadirat Tuhan Yang Maha Kuasa karena berkat rahmat dan anugerahNya sehingga penerbitan Vol. XIV No.2, Oktober 2018 MEDIA FARMASI POLITEKNIK KESEHATAN MAKASSAR dapat terlaksana dan telah mendapat legalitas sebagai media resmi dari Lembaga Ilmu Pengetahuan Indonesia (LIPI) dengan nomor penerbitan pISSN No. 0216-2083 dan e-ISSN No. 2622-0962.

Media Farmasi Politeknik Kesehatan Makassar merupakan suatu wadah dalam menampung aspirasi ilmiah sehingga dapat menggugah motivasi dan inovasi dari dosen di lingkup Jurusan Farmasi Politeknik Kesehatan Makassar serta artikel dari simpatisan untuk melakukan kajian ilmiah.

Media Farmasi Politeknik Kesehatan Makassar diterbitkan 2 kali dalam setahun yaitu pada bulan April dan Oktober. Sebagai majalah ilmiah, Media Farmasi mengembangkan misi dalam memajukan ilmu pengetahuan dan teknologi kesehatan khususnya di bidang farmasi

Akhirnya redaksi sangat berharap bahwa semua artikel yang disajikan dalam edisi ini dapat memberi apresiasi keilmuan di bidang kesehatan bagi kita semua. Oleh karena itu kritikan dan saran sangat kami harapkan demi kesempurnaan edisi-edisi selanjutnya.

Selamat membaca

Makassar, Oktober 2018

Redaksi 


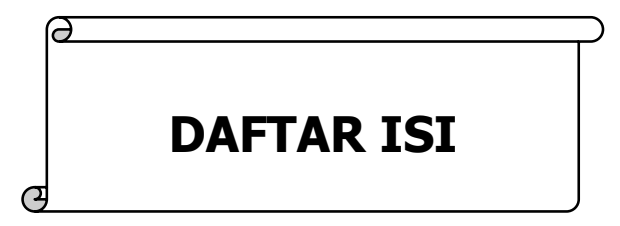

Pengaruh Pemberian Ekstrak Etanol Daun Afrika (Vernonia amygdalina

Del.) terhadap Kadar Asam Urat Darah Mencit Jantan (Mus musculus)

Jumain, Asmawati, Rini Karnita

Efektivitas Pemberian Rebusan Daun Pandan Wangi (Pandanus

Amaryllifolius Roxb.) terhadap Penurunan Kadar Glukosa Darah

Mencit (Mus musculus)

Amran Nur, Desi Reski Fajar, Musdalifah

Uji Efek Analgetik Infusa Jahe (Zingiber officinale Roscoe) terhadap Hewan Uji Mencit Jantan (Mus musculus)

Sisilia T. Rosmala Dewi, Hiany Salim.

Pengaruh Usia dan Tingkat Pendidikan terhadap Pemahaman Pasien

Setelah Pelayanan Informasi Obat di Puskesmas Makale Kabupaten

Tana Toraja Tahun 2018

Estherina Allo Payung, Septyani Mambela

Uji Daya Hambat Antibiotika Terhadap Bakteri Penyebab Infeksi

Saluran Kemih Di Rumah Sakit Salewangang Maros

Andi Dian Aulia Saudi, Rusdy

Uji Aktivitas Ekstrak Buah Pare (Momordica charantia L) terhadap Pertumbuhan Propionibacterium acnes

Dwi Rachmawaty Daswi, Asmawati

Analisis Kandungan Merkuri (Hg) pada Sediaan Krim Pemutih yang Beredar di Pasaran Kota Makassar dengan Menggunakan Metode Spektrofotometri Serapan Atom

Dedy Ma'ruf, Andi Asmawati, Ririn Muliana

Penentuan Total Polifenol Ekstrak Etanol Kulit Kecapi (Sandoricum koetjape) dari Lamasi Kabupaten Luwu

Santi Sinala, Minati, Alfrida Monica Salasa

Uji Potensi Antimikroba Hasil Fraksinasi Ekstrak Daun Kecombrang (Etlingera elatior) terhadap Candida albicans Penyebab Keputihan Pada Ibu Hamil

St. Ratnah, Alfrida Monica Salasa, H. Ismail Ibrahim 
Efek Konseling terhadap Tingkat Pengetahuan Ibu pada Terapi

Diare Balita

Khaerani, Surya Ningsi, Andi Try Resti Fauziah Sahib

Uji Daya Hambat Daun Tammate (Lannea coromandelica) terhadap

Bakteri Propionibacterium acnes dan Escherichia coli

Nurlaela, Abd.Karim, Taufiq Dalming

Efektivitas Ekstrak Air Buah Belimbing Wuluh (Averrhoa bilimbi)

Terhadap Pertumbuhan Propionibacterium acnes

Arisanty, Rara Puspa Dewi

Aktivitas Perasan Biji Pinang (Areca catechu L.) terhadap Pertumbuhan

Streptococcus mutans

Ikke Nurjanna, Hendra Stevani, Ratnasari Dewi

Evaluasi Tingkat Kepuasaan Pasien terhadap Pelayanan Kefarmasin di Depo IGD

Rumah Sakit TK II Pelamonia Makassar

Rahmawati, Desi Reski Fajar, Ira Widya Sari

78

Analisis Lama Waktu Tunggu Pelayanan Resep di Apotek BPJS

Rawat Jalan Rumah Sakit Pelamonia

Veronika Dampung, Ita Purnama Sari, Citra Rahayu, Rusli 